\title{
Radiological hip indices correlate with GMFCS level I and GMFM-66 scores in cerebral pasy
}

\author{
Özlem Elvan ${ }^{1}$ (D), Mert Keskinbora ${ }^{2}$ (D), Havva Didem Çelikcan ${ }^{3}$ (D), Alev Bobuş ${ }^{4}$ (D), Anıl Özgür ${ }^{5}$ (D), \\ Mustafa Kömür ${ }^{6}$ (iD), Zeliha Kurtoğlu Olgunus ${ }^{4}$ (iD \\ ${ }^{1}$ School of Health, Mersin University, Mersin, Turkey \\ ${ }^{2}$ Department of Orthopaedics and Traumatology, School of Medicine, Istanbul Medipol University, Istanbul, Turkey \\ ${ }^{3}$ Department of Biostatistics and Bioinformatics, School of Medicine, Mersin University, Mersin, Turkey \\ ${ }^{4}$ Department of Anatomy, School of Medicine, Mersin University, Mersin, Turkey \\ 'Department of Radiology, School of Medicine, Mersin University, Mersin, Turkey \\ ${ }^{6}$ Department of Pediatrics, School of Medicine, Mersin University, Mersin, Turkey
}

\begin{abstract}
Objectives: The aim of this study was to evaluate the certain radiological hip parameters and the effects of these parameters on the functional capacity of cerebral palsy (CP) children, to compare the Gross Motor Function Measure (GMFM-66 scores) of hemiparetic and diparetic children with spastic CP in Gross Motor Function Classification System (GMFCS) level 1, and to define possible differences or similarities with the control group.

Methods: The radiographic parameters measured for CP and control groups were caput-collum-diaphyseal angle (CCD), migration index (MI), center edge angle (CEA), acetabular index (AI) and pelvic obliquity. The functional capacity of the CP group was assessed by GMFM-66.

Results: No significant differences were found in terms of sides of the same individual in each group. Significant differences were found between groups for left CCD, right Ml, right and left Al, and right and left CEA. Correlation analyses revealed significant relationships between radiological parameters. Hemiparetics had statistically higher GMFM-66 dimension E score than diparetics.

Conclusion: The threshold values for hip parameters were determined with CP in GMFCS level 1. The hemiparetic and diparetic children with CP, who were at the GMFCS level I and age group, had similar hip morphology. Development of femoral head and acetabulum in these children were not different from control group. Evaluating the functional levels of patients according to GMFM-66 scores with radiographic parameters is believed to contribute to the monitoring CP children.

Keywords: cerebral palsy; functional capacity; gross motor functional classification system; gross motor function measure; radiographic hip parameters
\end{abstract}

Anatomy 2019;13(1):13-20 C2019 Turkish Society of Anatomy and Clinical Anatomy (TSACA)

\section{Introduction}

Cerebral palsy (CP) comprises a group of permanent disorders of the development of movement and posture, which causes activity limitations. ${ }^{[1]}$ Children with unilateral lesions are termed hemiparetic and children with bilateral lesions are termed diparetic. Hemiparetic group compared with the diparetic group with within the same Gross Motor Function Classification System (GMFCS) level would have better gait and lower extremity function, but worse upper extremity function. Children with hemiparetic CP tend to walk at an earlier age than those with diparetic. $^{[2,3]}$

The hip joint plays a key role for the lower limb alignment, and deformity of this joint gives rise to function impairments in the lower limb. ${ }^{[4,5]}$ Because of the muscle impairment during the growth phase, $15-20 \%$ of overall children population affected by CP have the risk of developing hip dislocation. A high correlation of hip dislocation 
with the level of GMFCS has been reported. ${ }^{[5]}$ Therefore, the functional capacity of the CP patients is affected and the quality of daily living activities decreases. ${ }^{[6]}$

The GMFCS was standardized as a method of classifying CP children by their level of functional mobility. ${ }^{[7]}$ The GMFCS is a simple, valid, and objective classification method that consists of five levels. Level I, children with minimal or no disability with respect to community mobility; level II, children with limitations walking indoors and outdoors but not using devices; level III, children with limitations walking indoors and outdoors and using assistive devices; level IV, children using methods of mobility that require physical assistance or powered mobility in most settings; level $\mathrm{V}$, children who are totally dependent on external assistance for mobility. ${ }^{[2,3,7,8]}$

Hip diseases are followed by surveillance programs in $\mathrm{CP}$ patients. This program encompasses the processes of the early identification and intervention of hip pathologies. ${ }^{[4,90]}$ Data obtained by clinical examination and radiological imaging are the vital components of the program. ${ }^{[4,5,9-14]}$ The Gross Motor Function Measure (GMFM-66) is used to measure changes in gross motor function over time or to evaluate interventions in $\mathrm{CP}$ patients. ${ }^{[15,16]}$ The GMFM is a criterian-referenced observational measure to assess children with CP. It measures the the items of gross motor activitiea in five dimensions; A: lying and rolling, B: sitting, C: crawling and kneeling, D: standing, and E: walking, running and jumping. ${ }^{[16]}$

Hip dislocation/subluxation causes significant morbidity in CP patients with advanced GMFCS. It is rarely a problem in ambulatory and mild forms of CP (GMFCS level 1). ${ }^{[15,16]}$ Although these types of $\mathrm{CP}$ children have been followed up, we have not encountered the data regarding the radiological hip indices. The aim of this study was to evaluate the certain radiological hip parameters and the effects of these parameters on the functional capacity of CP children, and to compare the GMFM-66 scores of hemiparetic and diparetic children with spastic $\mathrm{CP}$ in GMFCS level I. Also, control group with healthy hips were used to define possible differences or similarities with the CP group.

\section{Materials and Methods}

The antero-posterior radiographs (Hofmann DMT GmBH Selector D2 and Siemens Multix Tap equipments, Siemens Healthcare GmbH, Elangen, Eermany) of hips of the CP group in a standard technique in prone position ${ }^{[17]}$ obtained at our institution were reviewed retrospectively. The CP group, followed at the Department of Child Neurology, was consisted of 34 children with spastic CP (24 right-sided hemiparetic and 10 diparetic) with GMFCS level I. Descriptive values of those with relevant to gender and age were shown in Table $\mathbf{1}$. Evaluation of the motor function capacity of the $\mathrm{CP}$ group according to the crawling and kneeling $(\mathrm{C})$, standing (D) and walking (E) dimensions of the GMFM- $66^{[12]}$ was taken at their routine examination visits. Children with history of spine or hip operation, botulinum toxin injections, GMFCS level II-V, hypotonic/dyskinetic CP, uncoordinated children and low quality images were excluded. The control group consisted of 26 children submitted to the emergency department because of trauma. Descriptive values of this group were given in Table 1. The graphics excluding dislocation and broken hips, legs and spine were chosen carefully from the archive. The appropriate dosed and standardized positioned ones were taken into account for the study. ${ }^{[17]}$ The graphics were digitalized by a CR device then evaluated at the KODAK workstation by a radiologist. The study was carried out according to the principles of the Declaration of Helsinki. The ethical approval was taken from the Clinical Research Ethics Committee of Mersin University. The following radiographic parameters for each hip measured for both groups were (Figures $\mathbf{1}$ and 2): The caput-collum-diaphyseal (CCD) angle: The angle formed between the femoral neck and shaft in the frontal plane (Figure 1a); ${ }^{[6,18]}$ Migration index (MI): The percentage of the distance between the lateral cortex of the femoral head and the lateral margin of acetabulum to the distance between the lateral and medial cortex of the femoral head (Figure 1b); ${ }^{[5,10,12,1,1,1]}$ Center edge angle (CEA): The angle between a line drawn from the center of the femoral head to the outer edge of the acetabular roof and a vertical line drawn through the center of the femoral head (Figure 1c) ${ }^{[12,19-21]}$ Acetabular index (AI): The angle formed between the Hilgenreiner line and a line extending along the acetabular roof (Figure 1d); ${ }^{[5,12,19-21]}$ Pelvic obliquity (PO): The angle formed between the line connecting both inferior margins of the pubis and the horizontal line extending from the inferior pubis (Figure 1d). ${ }^{[12,22]}$

Table 1

Descriptive value of the hemiparetic, diparetic and control groups.

\begin{tabular}{lccc}
\hline & \multicolumn{2}{c}{ Gender } & \\
\cline { 2 - 3 } & Female (n) & Male (n) & Years of age \\
\hline Hemiparetic & 10 & 14 & $7.5 \pm 2.4$ \\
Diparetic & 4 & 6 & $8.4 \pm 3.1$ \\
Control & 16 & 10 & $10 . \pm 2$ \\
\hline
\end{tabular}


The Shapiro Wilk test was used to control normality of the continuous measurements. The distribution was normal in terms of hip parameters and one-wayANOVA test was used to compare group differences. Levene test was used to check homogeneity of variances. Differences between groups were tested by the Bonferroni post-hoc test. The paired sample t-test was used for differences between the left and right measurements in each group. Correlation between variables was investigated by calculating the Pearson correlation coefficient. Mean and standard deviation values were given as descriptive statistics, except PO. For PO, the median and quartile values were given and the Kruskal-Wallis test was employed for comparison between the groups. Also, because of not normally distributed scores, the median and quartile values are given and, Mann-Whitney $U$ test was used to compare the CP groups in terms of GMFM66 dimensions. SPSS Trial version was used for all statistical analysis. For the statistical significance $\mathrm{p}<0.05$ was adopted.

\section{Results}

The descriptive values of radiological parameters except $\mathrm{PO}$, regarding hemiparetic and diparetic $\mathrm{CP}$ children, and the control group were given in Table 2. The comparisons of these parameters within and between groups were analyzed in Table 2 . No significant differences were found in terms of sides of the same individual in each group ( $p>0.05)$. Significant differences were found between groups for left CCD, right MI, right and left AI, and right and left CEA $(\mathrm{p}<0.05)$. When pair-wise comparisons were examined, it was observed that there was a significant difference for left CCD between hemiparetic $(146.42 \pm 9.17)$ and diparetic $(154.30 \pm 7.32)$ cases $(\mathrm{p}=0.022)$. There was a significant difference for right MI between diparetic $(0.19 \pm 0.12)$ and the control groups $(0.09 \pm 0.05)$, $(\mathrm{p}=0.002)$. There were significant differences for right AI between hemiparetic $(11.95 \pm 3.05)$ and control groups $(9.50 \pm 3.13)$, and diparetic $(12.67 \pm 4.56)$ and control $(9.5 \pm 3.13)$ groups $(\mathrm{p}=0.02$ and $\mathrm{p}=0.019$, respectively).
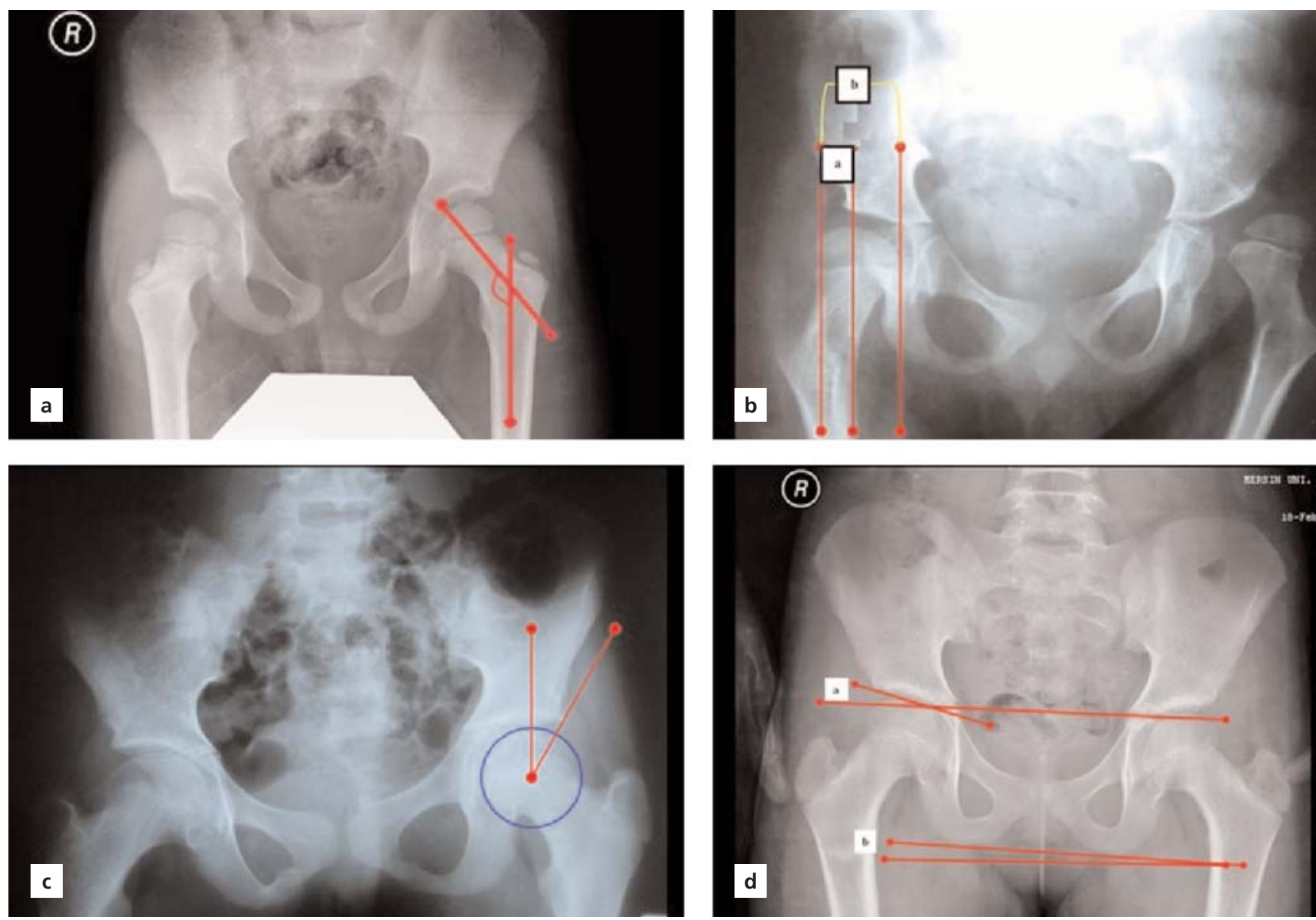

Figure 1. (a-d) The antero-posterior radiographics showing certain hip parameters. (a) Acetabular index diaphyseal angle (CCD). (b) Migration index $(\mathrm{MI})=(\mathrm{a} / \mathrm{b}) \times 100$. (c) Center edge angle (CEA). (d) Acetabular index (Al). a: acetabular index; b: pelvic obliquity (PO). 
Table 2

Comparisons of certain radiological parameters within and between groups.

\begin{tabular}{|c|c|c|c|c|c|}
\hline & & $\begin{array}{c}\text { Control } \\
n=26\end{array}$ & $\begin{array}{l}\text { Right hemiparetic } \\
n=24\end{array}$ & $\begin{array}{c}\text { Diparetic } \\
n=10\end{array}$ & $p^{a}$ \\
\hline \multirow[t]{3}{*}{$C C D$} & $R$ & $147.69 \pm 6.84$ & $149.52 \pm 9.34$ & $152.90 \pm 6.2$ & 0.199 \\
\hline & L & $148.85 \pm 5.41$ & $146.42 \pm 9.17$ & $154.30 \pm 7.32+$ & 0.027 \\
\hline & $p^{b}$ & 0.259 & 0.058 & 0.285 & \\
\hline \multirow[t]{3}{*}{ MI \% } & $R$ & $0.09 \pm 0.05$ & $0.13 \pm 0.07$ & $0.19 \pm 0.12^{*}$ & 0.003 \\
\hline & $\mathrm{L}$ & $0.09 \pm 0.05$ & $0.11 \pm 0.07$ & $0.14 \pm 0.08$ & 0.154 \\
\hline & $p^{b}$ & 0.565 & 0.351 & 0.335 & \\
\hline \multirow[t]{3}{*}{$\mathrm{Al}$} & $R$ & $9.50 \pm 3.13$ & $11.95 \pm 3.05^{\star}$ & $12.67 \pm 4.56^{\star}$ & 0.017 \\
\hline & L & $8.81 \pm 2.71$ & $12.11 \pm 4.48^{*}$ & $11.40 \pm 3.4$ & 0.008 \\
\hline & $p^{b}$ & 0.098 & 0.848 & 0.370 & \\
\hline \multirow[t]{3}{*}{ CEA } & $R$ & $34.85 \pm 5.18$ & $28.31 \pm 5.18^{*}$ & $28.13 \pm 3.87 *$ & $<0.001$ \\
\hline & $\mathrm{L}$ & $34.88 \pm 5.57$ & $30.58 \pm 5.75^{*}$ & $31.70 \pm 6.2$ & 0.044 \\
\hline & $p^{b}$ & 0.961 & 0.101 & 0.395 & \\
\hline
\end{tabular}

$\mathrm{p}^{\mathrm{a}}$ : $\mathrm{p}$-value of one-way ANOVA test; $\mathrm{p}^{\mathrm{b}}$ : $\mathrm{p}$-value of paired $\mathrm{t}$ test; ${ }^{*}$ indicator of difference with control group; ${ }^{\dagger}$ indicator of difference with hemiparetic group; Al: acetabular index; CCD: caput-collum-diaphyseal angle; CEA: center edge angle; MI: migration index; L: left side; R: right side.

There was a significant difference for left AI between hemiparetic $(12.11 \pm 4.48)$ and the control $(8.81 \pm 2.71)$ groups $(\mathrm{p}=0.003)$. There were significant differences for right CEA between hemiparetic $(28.31 \pm 5.18)$ and the control $(34.85 \pm 5.18)$ groups, and diparetic $(28.13 \pm 3.87)$ and control $(34.85 \pm 5.18)$ groups $(\mathrm{p}=0.001$ and $\mathrm{p}=0.005$, respectively). There was a significant difference for left CEA between hemiparetic $(30.58 \pm 5.75)$ and the control $(34.88 \pm 5.57)$ groups $(\mathrm{p}=0.049)$.

For the PO, the median and $25-75 \%$ quartile values were: $1^{\circ}$ and $0-3^{\circ}$ for hemiparetics, 4 and $1-5$ for diparetics, 10 and $0-30$ for the control group. No significant difference was found between the hemiparetic, diparetic and control groups $(\mathrm{p}=0.163)$. Correlation analyses unveiled significant relationships between radiological parameters (Table 3). The scores of functional capacity of CP children measured with GMFM-66 were given in Table 4.

\section{Discussion}

The GMFCS have the advantages of reliability, validity and simple applicability. However, a significant ambiguity was reported in distinguishing level I from level II. ${ }^{[23]}$ For further reliable classifications, we analyzed the radiological hip parameters of the children with GMFCS level I spastic type $\mathrm{CP}$ and evaluated their functional capacity according to these outcomes.

Although CCD angle was reported to have a high variance, it is normally measured approximately $150^{\circ}$ in newborns, $135^{\circ}$ at six years of age, $120-130^{\circ}$ in adults, and $147^{\circ}$ to $154^{\circ}$ in $\mathrm{CP}$ children. ${ }^{[6,18,24]}$ In the present study, the age distribution of children, both in CP and control groups, was between 5 to 12 years of age. Although, a certain CCD angle has not been described for these ages, the mean CCD angle of our cases has found to be over the average that was reported for the 6 years old group. When we compared the CCD angles of $\mathrm{CP}$ and control groups, the CCD angles in left hips of diparetics were found to be statistically significantly higher than left hips of hemiparetics $(\mathrm{p}=0.027)$. In the literature, where the CCD angle is reported to be high in $\mathrm{CP}$ patients, none of them have reported the specific angle values according to the $\mathrm{CP}$ subtype. ${ }^{[6,13]}$ Particularly, no difference related to the CCD angle was observed in hemiparetic CP children in our study. Additionally, the CCD angle was found to have a positive correlation between sides in each group (Table 3).

The CCD angle and MI is reported to be significantly higher in GMFCS level IV-V quadriparetic patients than in the GMFCS level I-III diparetic patients. As well as, when there is a positive correlation between MI and CCD angles, a tendency to develop coxa valga is observed in the hips with higher MI values. ${ }^{[25]}$ Our study demonstrated higher MI values in the right hips of diparetic CP cases than in the control group, while a powerful positive correlation was determined between CCD angle and MI (Table 3). According to the findings of the study, due to the mild increase of CCD in CP group, there need to be monitored closely in terms of coxa valga. 
Table 3

Correlations between radiological parameters of the hemiparetic and diparetic CP groups.

\begin{tabular}{|c|c|c|c|c|c|c|c|c|c|}
\hline & & & CCD-L & MI-R & MI-L & Al-R & Al-L & CEA-R & CEA-L \\
\hline \multirow[t]{14}{*}{ Right hemiparetic } & CCD-R & r & $0.738^{*}$ & -0.092 & -0.404 & $-0.464^{\dagger}$ & -0.531 * & -0.193 & 0.140 \\
\hline & & $\mathrm{p}$ & $<0.001$ & 0.708 & 0.086 & 0.046 & 0.019 & 0.428 & 0.568 \\
\hline & CCD-L & r & 1 & -0.055 & -0.310 & -0.337 & -0.220 & -0.148 & 0.077 \\
\hline & & $p$ & & 0.822 & 0.197 & 0.158 & 0.366 & 0.545 & 0.753 \\
\hline & Ml-R & $r$ & & 1 & 0.417 & 0.373 & 0.146 & -0.533 & 0.037 \\
\hline & & $\mathrm{p}$ & & & 0.076 & 0.116 & 0.550 & $0.019^{\dagger}$ & 0.879 \\
\hline & Ml-L & $r$ & & & 1 & $0.502^{+}$ & $0.576^{*}$ & -0.132 & $-0.519^{\dagger}$ \\
\hline & & $\mathrm{p}$ & & & & 0.028 & 0.010 & 0.590 & 0.023 \\
\hline & Al-R & r & & & & 1 & $0.619 *$ & $-0.461^{\dagger}$ & -0.423 \\
\hline & & $\mathrm{p}$ & & & & & 0.005 & 0.047 & 0.071 \\
\hline & Al-L & $r$ & & & & & 1 & -0.169 & $-0.695^{\star}$ \\
\hline & & $\mathrm{p}$ & & & & & & 0.489 & 0.001 \\
\hline & CEA-R & $r$ & & & & & & 1 & $0.459^{\dagger}$ \\
\hline & & $\mathrm{p}$ & & & & & & & 0.048 \\
\hline \multirow[t]{14}{*}{ Diparetic } & $C C D-R$ & $r$ & $0.847^{*}$ & $0.701^{\dagger}$ & 0.005 & 0.565 & -0.366 & $-0.738^{\dagger}$ & 0.253 \\
\hline & & $p$ & 0.002 & 0.024 & 0.989 & 0.113 & 0.299 & 0.015 & 0.480 \\
\hline & CCD-L & $r$ & 1 & 0.258 & 0.072 & 0.160 & $-0.670^{\dagger}$ & -0.314 & 0.002 \\
\hline & & $p$ & & 0.471 & 0.844 & 0.680 & 0.034 & 0.376 & 0.995 \\
\hline & Ml-R & $r$ & & 1 & -0.033 & $0.828^{*}$ & 0.171 & $-0.953^{*}$ & 0.449 \\
\hline & & $\mathrm{p}$ & & & 0.928 & 0.006 & 0.638 & $<0.001$ & 0.193 \\
\hline & Ml-L & $r$ & & & 1 & -0.051 & 0.049 & 0.212 & $-0.841 *$ \\
\hline & & $\mathrm{p}$ & & & & 0.896 & 0.893 & 0.556 & 0.002 \\
\hline & Al-R & $r$ & & & & 1 & 0.487 & $-0.782^{\dagger}$ & 0.335 \\
\hline & & $\mathrm{p}$ & & & & & 0.184 & 0.013 & 0.378 \\
\hline & Al-L & $r$ & & & & & 1 & -0.100 & -0.025 \\
\hline & & $p$ & & & & & & 0.783 & 0.945 \\
\hline & CEA-R & $r$ & & & & & & 1 & -0.536 \\
\hline & & $\mathrm{p}$ & & & & & & & 0.110 \\
\hline \multirow[t]{14}{*}{ Control } & CCD-R & $r$ & $0.677^{*}$ & 0.115 & 0.125 & -0.232 & -0.094 & -0.205 & -0.110 \\
\hline & & $\mathrm{p}$ & $<0.001$ & 0.576 & 0.542 & 0.254 & 0.648 & 0.316 & 0.592 \\
\hline & CCD-L & $r$ & 1 & 0.319 & 0.126 & -0.194 & -0.095 & -0.176 & -0.030 \\
\hline & & $p$ & & 0.112 & 0.540 & 0.343 & 0.645 & 0.389 & 0.885 \\
\hline & Ml-R & $r$ & & 1 & $0.762^{*}$ & $0.427^{\dagger}$ & 0.374 & $-0.667 *$ & $-0.504^{*}$ \\
\hline & & $p$ & & & $<0.001$ & 0.029 & 0.060 & $<0.001$ & 0.009 \\
\hline & MI-L & $r$ & & & 1 & $0.432^{+}$ & $0.598 *$ & -0.551 * & $-0.729 *$ \\
\hline & & $\mathrm{p}$ & & & & 0.028 & 0.001 & 0.004 & $<0.001$ \\
\hline & Al-R & $r$ & & & & 1 & $0.761^{*}$ & $-0.620^{*}$ & $-0.678^{*}$ \\
\hline & & $\mathrm{p}$ & & & & & $<0.001$ & 0.001 & $<0.001$ \\
\hline & Al-L & $r$ & & & & & 1 & -0.551 * & $-0.742^{*}$ \\
\hline & & $\mathrm{p}$ & & & & & & 0.004 & $<0.001$ \\
\hline & CEA-R & $r$ & & & & & & 1 & $0.729 *$ \\
\hline & & $p$ & & & & & & & $<0.001$ \\
\hline
\end{tabular}

Al: acetabular index; CCD: caput-collum-diaphyseal angle; CEA: center edge angle; MI: migration index; L: left side; $R$ : right side. ${ }^{\star} p<0.001,{ }^{\dagger} p<0.05$.

The mean AI angle between 5 to 11 years of age was reported to be $12.9 \pm 4.5^{\circ}$ and the upper limit for normal coverage was accepted as $22^{\circ} .^{[20]}$ The $\mathrm{AI}$ angle was reported to be similar in spastic patients with stable and normal hips. ${ }^{[26]}$ In our study, the mean AI angle was found to be within the normal limits in all groups. However, the AI parameter of hemiparetics was found to be higher in both hips than in the control group. Also, it was found to be higher in right of the diparetics than the control group (Table 2). Although normal limits were found in the study, the greater values in CP patients reflect the higher acetabular inclination and the predisposition to hip displacement. 

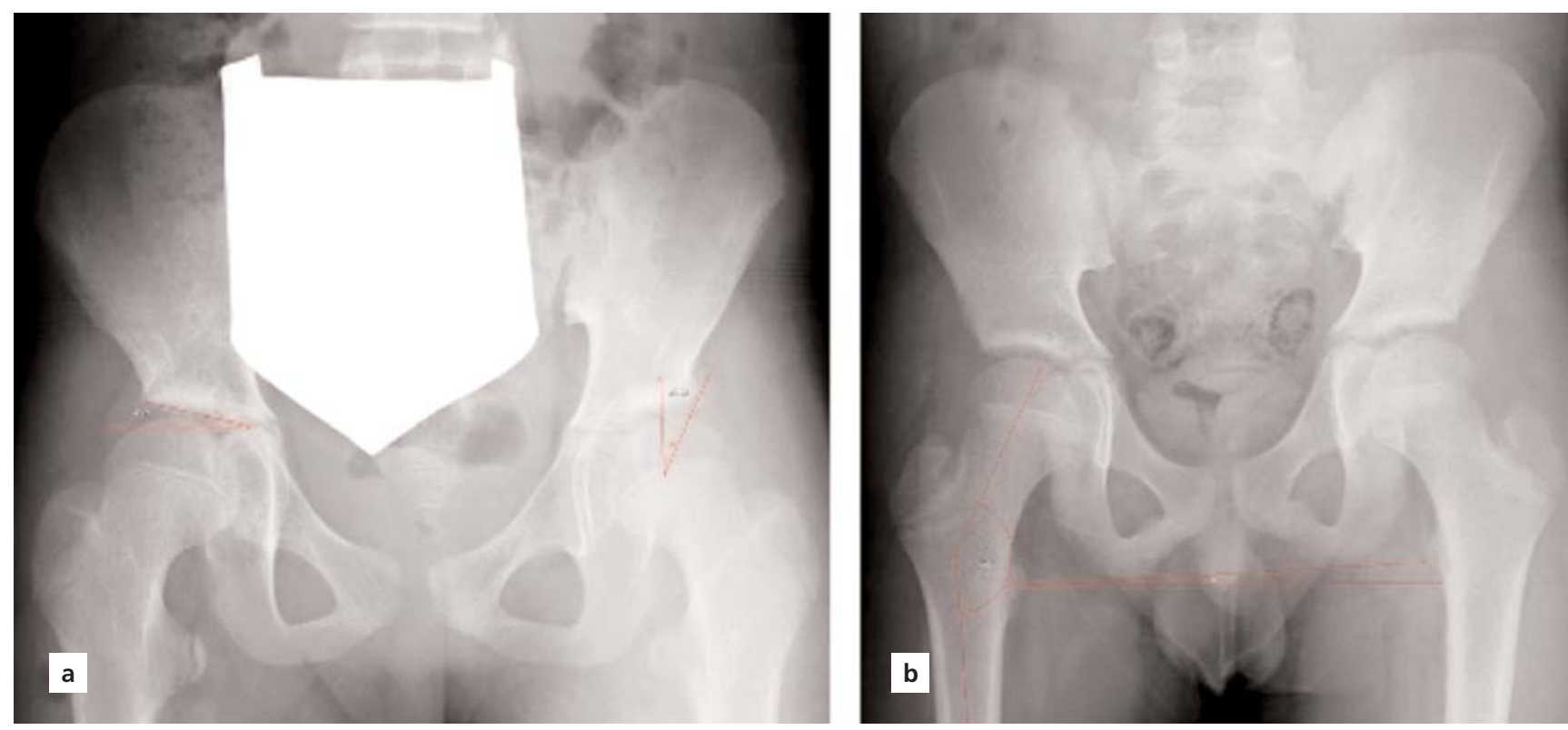

Figure 2. (a) Al on the right side and the CEA on the left side in diparetic CP girl aged 9 years. (b) The CCD on the right side and the PO on right side in hemiparetic CP boy aged 9 years. CCD: caput-collum-diaphyseal angle; CEA: center edge angle; CP: cerebral palsy; PO: pelvic obliquity.

The normal value of CEA for 5 to 10 years of age is reported to be $25.2 \pm 5.2^{\circ}$ and $30 \pm 5.6^{\circ}$ between 11 to 15 years of age. The lower limit of this angle between 5 to 10 years is $15^{\circ}$ and $19^{\circ}$ for 11 to 15 years of age. The CEA is reported to be a little bit higher in left hips, which is explained by the weight bearing differences between two sides. ${ }^{[20]}$ In this study, interestingly the CEA was found to be lower in both hips of hemiparetic CP children and in the right hips of diparetic CP children than in the control group. Terjesen indicated the relationship of MI with CEA and AI in CP patients. ${ }^{[12]}$ In the present study, negative correlation between CEA and MI parameters was observed in both hips of hemiparetics and diparetics. Similarly, negative correlation was found in both hips of hemiparetics and in the right hip of diparetics between CEA and AI (Table 3).

In comparing treatment outcomes, choosing children at the same age and the same GMFCS level is suggested in spite of normal children as control group. ${ }^{[7]} \mathrm{In}$ this study, comparison of hemiparetic and diparetic CP children in terms of hip sides revealed no statistically significant difference, except for the CCD angle in left hips. Therefore, we thought that the hip parameters of CP children at the same age and the GMFCS level I revealed similar morphology independent of the $\mathrm{CP}$ subtype.

Evaluation of the hemiparetic CP patients according to GMFM-66 revealed lack of ability in stability, kneeling and standing up activities. However, these cases were reported to have better activity scores when compared to other types of CP. According to gross motor development, diparetic CP patients were observed to have less ability, especially in standing and walking activities. In the same study, scores of GMFM-66 dimensions C, D and $\mathrm{E}$ for hemiparetic $\mathrm{CP}$ patients were $97 \pm 4.17 \%$, $84.78 \pm 10.72 \%$ and $84.61 \pm 8.32 \%$, and for diparetic CP patients $44.88 \pm 33.31 \%, 28.95 \pm 27.97 \%$ and $30.45 \pm$ $33.11 \%$, respectively. ${ }^{[2]}$ Significant differences between the scores were reported in that study as topographic distribution and GMFCS levels were ignored in evaluation phase. The results of this study demonstrated higher scores of GMFM-66 in the GMFCS level I hemiparetic and diparetic CP children (Table 4), in accordance with the previous report of Oeffinger et al. ${ }^{[3]}$

The "C" dimension of GMFM-66 includes more upper extremity involving activities than " $D$ " and "E". Although, hemiparetic CP patients are known to have better abilities in walking and lower extremity functions, they are reported to have lower capacity in upper extremity functions than diparetic CP patients. ${ }^{[2]}$ In this study, scores of hemiparetics in dimension " $\mathrm{E}$ " were found to be significantly higher than diparetics and scores of diparetics in dimension " $D$ " were found to be significantly higher than hemiparetics. However, no significant difference was observed between the two groups by means of "C" scores (crawling and kneeling activities). According to GMFM-66, hemiparetic children in GMFCS level I were found to have higher ability in 
Table 4

Comparison of GMFM-66 dimensions C-D-E between the hemiparetic and diparetic CP groups.

\begin{tabular}{|c|c|c|c|c|c|}
\hline & \multicolumn{2}{|c|}{ Right hemiparetic $(n=24)$} & \multicolumn{2}{|c|}{ Diparetic $(n=10)$} & \multirow[b]{2}{*}{ p-value } \\
\hline & Min-max & Median $(25-75 \%)$ & Min-max & Median (25-75\%) & \\
\hline C- crawling and kneeling & $81-100$ & $100(95-100)$ & $76-100$ & $98(81-100)$ & 0.163 \\
\hline D-standing & 64-100 & $70(68-74)$ & 54-100 & 87 (69-95) & 0.010 \\
\hline E-walking & $74-100$ & $92(82-96)$ & $46-100$ & 75 (52-97) & 0.029 \\
\hline
\end{tabular}

walking, running and jumping activities than diparetics. Our study results were compatible with this report (Table 4).

The present study has an important limitation regarding less number of study populations. Due to having q mild form of CP with GMFCS level I children need less interventional treatments. Nevertheless, finding CP children without botulinum toxin injections, cognitive impairments and hypotonic/dyskinetic types is difficult. In further studies, a larger study population or community based registry will be evaluated within all GMFCS levels.

\section{Conclusion}

Threshold values of certain radiographic parameters of the CP children with GMFCS level I were determined in the present study. The radiographic findings revealed that development of the femoral head and acetabulum was not different from the control group and the literature data. Accordingly, these results support the effect of walking on hip development and the protective role in hip biomechanics according to GMFM-66 scores.

\section{References}

1. Martins E, Cordovil R, Oliveira R, Letras S, Lourenço S, Pereira I, Ferro A, Lopes I, Silva CR, Marques M. Efficacy of suit therapy on functioning in children and adolescentswith cerebral palsy: a systematic review and meta-analysis. Dev Med Child Neurol 2016;58:34860.

2. Damiano D, Abel M, Romness M, Oeffinger D, Tylkowski C, Gorton G, Bagley A, Nicholson D, Barnes D, Calmes J, Kryscio R, Rogers. Comparing functional profiles of children with hemiplegic and diplegic cerebral palsy in GMFCS Levels I and II: are separate classifications needed? Dev Med Child Neurol 2006;48:797-803.

3. Oeffinger DJ, Rogers SP, Bagley A, Gorton G, Tylkowski CM. Clinical applications of outcome tools in ambulatory children with cerebral palsy. Phys Med Rehabil Clin N Am 2009;20:549-65.

4. Soo B, Howard JJ, Boyd RN. Hip displacement in cerebral palsy. J Bone Joint Surg Am 2006;88:121-9.

5. Hägglund G, Lauge-Pedersen H, Wagner P. Characteristics of children with hip displacement in cerebral palsy. BMC Musculoskelet Disord 2007;26:101.
6. Morrell DS, Pearson JM, Sauser DD. Progressive bone and joint abnormalities of the spine and lower extremities in cerebral palsy. Radiographics 2002;22:257-68.

7. Palisano R, Hanna SE, Rosenbaum P, Russell D, Walter SD, Wood EP, Galuppi BE. Validation of a model of gross motor function for children with cerebral palsy. Phys Ther 2000;80:974-85.

8. Cobanoglu M, Cullu E, Omurlu I. The effect of hip reconstruction on gross motor function levels in children with cerebral palsy. Acta Orthop Traumatol Turc 2018;52:44-8.

9. Hägglund G, Andersson S, Düppe H, Lauge-Pedersen H, Nordmark E, Westbom LJ. Prevention of dislocation of the hip in children with cerebral palsy. The first ten years of a population-based prevention programme. Bone Joint Surg Br 2005;87:95-101.

10. Dobson F, Boyd RN, Parrott J, Nattrass GR, Graham HK. Hip surveillance in children with cerebral palsy. J Bone Joint Surg Br 2002;84:720-6.

11. Wood E, Rosenbaum P. The Gross Motor Function Classification System for cerebral palsy: a study of reliability and stability over time. Dev Med Child Neurol 2000;42:292-6.

12. Terjesen T. Development of the hip joints in unoperated children with cerebral palsy. Acta Orthopaedica 2006;77:125-31.

13. Scrutton D, Baird G. Surveillance measures of the hips of children with bilateral cerebral palsy. Arch Dis Child 1997;76:381-4.

14. Rethlefsen SA, Ryan DD, Kay RM. Classification systems in cerebral palsy. Orthop Clin North Am 2010;41:457-67.

15. Günel MK. Rehabilitation of children with cerebral palsy from a physiotherapist's perspective. Acta Orthop Traumatol Turc 2009;43: 173-80.

16. Russell DJ, Avery LM, Rosenbaum PL, Raina PS, Walter SD, Palisano RJ. Improved scaling of the gross motor function measure for children with cerebral palsy: evidence of reliability and validity. Phys Ther 2000;80:873-85.

17. Grunert S, Brückl R, Rosemeyer B. Rippstein and Müller roentgenologic determination of the actual femoral neck-shaft and antetorsion angle. 1: Correction of the conversion table and study of the effects of positioning errors. Radiologe 1986;26:293-304.

18. Başaloğlu H, Akbaş A. İnsan femurlarında torsiyon ve kolladiafizer açıları, birbirleri arasındaki ilişkiler ve açı değerleri üzerinde etkili bazı faktörler. Acta Orthop Traumatol Turc 1996;30:299-302.

19. Suh DH, Hong JY, Suh SW, Park JW, Lee SH. Analysis of hip dysplasia and spinopelvic alignment in cerebral palsy. Spine J 2014;14: 2716-23.

20. Özçelik A, Ömeroğlu H, Ulukan İ, Seber İ. Türk toplumunda çocuk ve erişkinlerin normal kalçalarında merkez-kenar açısı (CE) değerleri. J Arthrop Arthros Surg 2001;12:115-9.

21. Omeroğlu H, Ozçelik A, Inan U, Seber S. Assessment of the correlation between commonly used radiographic parameters in normal, 
subluxated and dislocated hips. J Pediatr Orthop B 2006;15:1727.

22. Suh SW, Suh DH, Kim JW, Park JH, Hong JY. Analysis of sagittal spinopelvic parameters in cerebral palsy. Spine J 2013;13:882-8.

23. Reid SM, Carlin JB, Reddihough DS. Using the Gross Motor Function Classification System to describe patterns of motor severity in cerebral palsy. Dev Med Child Neuro 2011;53:1007-12.

24. Boese CK, Dargel J, Oppermann J, Eysel P, Scheyerer MJ, Bredow J, Lechler P. The femoral neck-shaft angle on plain radiographs: a systematic review. Skeletal Radiol 2016;45:19-28.
25. Gose S, Sakai T, Shibata T, Murase T, Yoshikawa H, Sugamoto K. Morphometric analysis of acetabular dysplasia in cerebral palsy: three-dimensional CT study. J Pediatr Orthop 2009;29:896902.

26. Chang CH, Kuo KN, Wang CJ, Chen YY, Cheng HY, Kao HK. Acetabular deficiency in spastic hip subluxation. J Pediatr Orthop 2011;31:648-54.

27. Hazneci B, Vurucu S, Örs F, Tan AK, Gençdoğan S, Dinçer K, Kalyon TA. Factors affecting the functional level in children with cerebral palsy. Turk J Phys Med Rehab 2006;52:105-9.

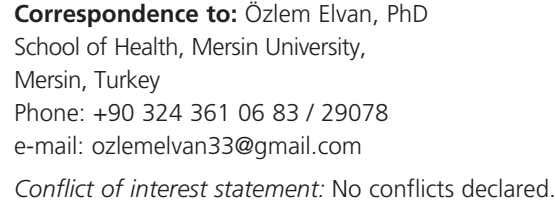

This is an open access article distributed under the terms of the Creative Commons Attribution-NonCommercial-NoDerivs 3.0 Unported (CC BY-NC-ND3.0) Licence (http://creativecommons.org/licenses/by-nc-nd/3.0/) which permits unrestricted noncommercial use, distribution, and reproduction in any medium, provided the original work is properly cited. Please cite this article as: Elvan Ö, Keskinbora M, Çelikcan HD, Bobuş A, Özgür A, Kömür M, Kurtoğlu Olgunus Z. Radiological hip indices correlate with GMFCS level I and GMFM-66 scores in cerebral pasy. Anatomy 2019;13(1):13-20. 